3 oesophageal ulcers). 12\% (6 of 50) had oesophageal cancer. A further 10 had hiatus hernia, 1 had a motility disorder and 1 had oesophageal diverticulum.

Conclusion From this study, 68\% of patients endoscoped for odynophagia have a positive endoscopic mucosal abnormality. Odynophagia as a symptom has a high sensitivity for abnormal endoscopy. $12 \%$ of patients endoscoped for odynophagia had oesophageal cancer. This prevalence is similar to the diagnosis of cancer in patients referred on the 'two week wait upper GI cancer referral form'. We recommend the symptom of odynophagia be classified as an alarm symptom and those presenting with odynophagia all undergo upper GI endoscopy to define the exact mucosal abnormality and exclude oesophageal cancer.

Disclosure of Interest None Declared.

\section{PTU-052 DOES USE OF SEDATION AFFECT THE SPEED AT WHICH ENDOSCOPY IS PERFORMED AND NUMBER OF BIOPSIES OBTAINED IN BARRETT'S OESOPHAGUS?}

S Subramaniam*, H Defoe, A Chitembwe, J Ferrera, K Besherdas. Department of Gastroenterology, Barnet and Chase Farm NHS Trust, London, UK

\subsection{6/gutjnl-2014-307263.126}

Introduction Guidelines for Barrett's oesophagus (BE) screening recommend 2 yearly endoscopies with 4 quadrant biopsies every $2 \mathrm{~cm}$ for $\mathrm{BE}$ without dysplasia. There is increasing evidence that longer inspection time of $\mathrm{BE}$ segment is associated with increased detection of high-grade dysplasia and oesophageal cancer. In our experience, BE surveillance endoscopies have been undertaken both with and without sedation as no formal guidelines recommend use of one method over the other. Endoscopic procedures may be quicker in the unsedated patient and therefore these are likely to have lower Barrett's inspection time (BIT) and also fewer biopsies than in sedated patients. The aim of our study was to assess the prevalence of sedation use in $\mathrm{BE}$ surveillance endoscopy and to determine if this affected the time taken for the procedure and the number of biopsies obtained.

Methods A retrospective analysis of all patients who underwent surveillance endoscopy for BE over a 5 year period (2009-2013) in a large district general hospital in North London were identified using the audit tool on Unisoft Endoscopy reporting software. Data collection was done by endoscopy unit nursing staff. From each report, use of sedation, length of BE and number of biopsies taken from BE segment were recorded. The time taken for each BE endoscopy was also obtained from procedure logbooks. The mean length of time (LOT) per procedure was compared between sedated and unsedated endoscopies using a t test. A multiple linear regression fit was performed on the data using regressors sedation values, length of $\mathrm{BE}$ and number of biopsies taken.

Results 181 endoscopies for BE surveillance were performed over 5 years. 37 were excluded as insufficient data was available. Of the 144 endoscopies remaining, 73 were unsedated and 71 with sedation. The mean LOT for sedated compared with unsedated endoscopies was $12.47 \mathrm{~min}$ and $10.36 \mathrm{~min}$ respectively ( $\mathrm{p}$ $=0.05$, confidence interval $=-4.23,0.01)$. The average number of biopsies in sedated patients was 3.87 and 3.85 in the unsedated $(\mathrm{p}=0.47)$. The regression was a poor fit $\left(\mathrm{R}^{2}\right.$ adjusted $=$ $-0.00033)$ and the overall relationship not significant: $\mathrm{F}(2,141)$ $=0.976, \mathrm{p}=0.38$. $\mathrm{P}$ values for sedation $(\mathrm{p}=0.96)$ and length of $\mathrm{BO}(\mathrm{p}=0.16)$ did not achieve significance either.

Conclusion In our study of patients undergoing endoscopy for BE surveillance, the LOT of endoscopic procedure was greater in patients receiving sedation than unsedated patients. The length of $\mathrm{BE}$ or the use of sedation did not have a significant effect on the number of biopsies taken. Sedation use did not affect number of biopsies obtained and therefore may not increase dysplasia detection. We conclude that surveillance for BE patients can be performed without sedation.

Disclosure of Interest None Declared.

\section{PTU-053 IS IT WORTH REPEATING PREVIOUS UNREMARKABLE SB2 CAPSULES WITH THE NEW SB3?}

S Dunn*, R Bevan, L Neilson, R Keay, C Davison, F Butt, S Panter. South Tyneside NHS Foundation Trust, South Shields, UK

\subsection{6/gutjnl-2014-307263.127}

Introduction Small bowel capsule endoscopy (SBCE) has become a valuable tool for investigating the small bowel and technology is rapidly advancing. One of the most recent devices available for capsule endoscopy (Pillcam ${ }^{\circledR}$ SB3, Given Imaging) has improved image resolution and a variable frame rate. The aim of this work is to address whether these innovations lead to increased mucosal visualisation and diagnostic yield in clinical practice and therefore whether a repeat SB3 capsule should be considered in those patients with an equivocal SB2 result.

Methods A review was undertaken of the last 100 Pillcam ${ }^{\circledR}$ SB2 capsules and the first 55 Pillcam ${ }^{\circledR}$ SB3 capsules to be performed at South Tyneside District Hospital (14/01/13-12/12/13). Visualisation of the ampulla was used as a surrogate marker of mucosal visualisation and diagnostic yield was assessed by reviewing the reports. Statistical significance was calculated using Fisher's exact test.

Results Results are summarised in Table 1 below. The ampulla was visualised in 14\% of SB2 capsules and 18\% of SB3 capsules ( $p>0.05$ ). $44 \%$ of SB2 capsules were abnormal and SB3 capsules were abnormal in $62 \%$ of cases $(p<0.05)$.

Conclusion It is recognised that the views obtained by SBCE can be compromised in the duodenum due to "rapid transit" and previous studies have suggested that due to this the ampulla of Vater is not often seen. ${ }^{1}$ Variable frame rates aim to address this by capturing more images when the capsule is moving quicker. We showed no statistically significant difference between ampullary visualisation of the SB2 and SB3 capsules, although the trend was to a higher percentage visualisation with the SB3 capsule. The overall yield of pathology from SB3 capsules was significantly higher than that in SB2 capsules. Given the overall increased yield of pathology it may be beneficial to repeat an SB3 capsule in someone with a previously equivocal SB2 result.

\begin{tabular}{llll}
\multicolumn{4}{l}{ Abstract PTU-053 Table 1} \\
\hline Capsule type & Number & Ampulla seen (\%) & Pathology found (\%) \\
\hline SB2 & 100 & $14(14 \%)$ & $44(44 \%)$ \\
SB3 & 55 & $10(18 \%)$ & $34(62 \%)$ \\
p value & & 0.495 & 0.044 \\
\hline
\end{tabular}

\section{REFERENCE}

1 Koulaouzidis A, Rondonotti E, Karargyris A. Small-bowel capsule endoscopy: A ten-point contemporary review. World Journal of Gastroenterology 2013;19 (24):3726-2840

Disclosure of Interest S. Dunn Grant/research support from: Aquilant Endoscopy, R. Bevan Grant/research support from: 
Aquilant Endoscopy, L. Neilson: None Declared, R. Keay: None Declared, C. Davison: None Declared, F. Butt: None Declared, S. Panter: None Declared.

\section{PTU-054 TRANSNASAL GASTROSCOPY - ARE THE BIOPSIES SUITABLE FOR BARRETT'S SURVEILLANCE?}

S Fox*. Endoscopy, Braintree Community Hospital, Braintree, UK

\subsection{6/gutjnl-2014-307263.128}

Introduction Transnasal gastroscopy is a far more acceptable form of gastroscopy to the patient, with benefits including reduced gagging, ability to communicate during the procedure, greater flexibility of endoscope allowing easier visualisation of difficult areas and closer inspection of the laryn $\mathrm{x} .{ }^{1}$

Due to the smaller working channel, $2.0 \mathrm{~mm}$ as compared with $2.8 \mathrm{~mm}$ of a standard oral gastroscope, the biopsy forceps used in transnasal gastroscopy are smaller, leading to questions about the suitability of transnasal gastroscopy for Barrett's surveillance.

As an early adopter of transnasal gastroscopy, Braintree community hospital endoscopy service has performed many thousands of diagnostic transnasal gastroscopies including Barrett's surveillance. This study compares the dysplasia and malignancy rate of transnasal gastroscopy biopsies and oral gastroscopy biopsies.

Methods All patients attending for a follow up gastroscopy for Barrett's surveillance over the past three years were included in the study.

Patients attending for gastroscopy are sent information on the types of procedure when the appointment is booked. The patient is free to choose whichever form of gastroscopy they wish. On admission, the nurse will explain both procedures again and the patient will then choose. The vast majority choose to have transnasal gastroscopy.

For those that choose to have oral gastroscopy, a standard oral gastroscope is used rather than a transnasal gastroscope.

All endoscopists take quadrantic biopsies of the Barrett's segment in accordance with the BSG guidelines.

The study looked back at 3 years of Barrett's surveillance and compared the rates of dysplasia found in the transnasal series and the oral series. The overall dysplasia rate, including adenocarcinoma, was compared.

Results In the three year period there were a total of 1282 patients who underwent Barrett's surveillance.

Of these, 905 (70.6\%) chose to have transnasal gastroscopy, the remainder, 377 (29.4\%) chose to have oral gastroscopy.

Of the transnasal series, $12(1.3 \%)$ had LGD, $5(0.6 \%)$ had HGD, 3(0.3\%) had ACA and $9(1 \%)$ were indefinite for dysplasia.

Of the oral series, $7(1.8 \%)$ had LGD, $0(0 \%)$ had HGD, 2 $(0.5 \%)$ had ACA and 7 (1.8\%) were indefinite for dysplasia.

The overall dysplasia and malignancy rate in the trans nasal group versus the oral group was $2.2 \%$ vs. $2.4 \%(\mathrm{p}=0.4048)$. Conclusion Our series at Braintree community hospital shows that there is not a significant difference in the dysplasia and malignance rate found on transnasal biopsies as compared with oral gastroscopy biopsies.

\section{REFERENCE}

1 Knuth J, Kunze DE, Benz C, Bullian DR, Heiss MM, Lefering R, Saad S, Saers T, Krakamp B. Is the transnasal access for esophagogastroduodenoscopy in routine use equal to the transoral route? A prospective, randomized trial. $Z$ Gastroenterol 2013 Dec:51(12):1369-1376

Disclosure of Interest None Declared.
PTU-055 A COMPARISON OF RADIOLOGICAL AND ENDOSCOPIC OESOPHAGEAL STENT PLACEMENT IN MALIGNANCY

${ }^{1} \mathrm{~T}$ Chapman*, ${ }^{1} \mathrm{H}$ Tyrell, ${ }^{1} \mathrm{H}$ Al-Hassani, ${ }^{1} \mathrm{~A}$ Colcer, ${ }^{1} \mathrm{~A}$ Bruce, ${ }^{1} \mathrm{~N}$ Rajoriya, ${ }^{2} \mathrm{D}$ Warakaulle, ${ }^{1} \mathrm{D}$ Gorard, ${ }^{1} \mathrm{R}$ Sekhar. ${ }^{1}$ Department of Gastroenterology, Wycombe and Stoke Mandeville Hospitals, Buckinghamshire Healthcare NHS Trust, Buckinghamshire, UK; ${ }^{2}$ Department of Radiology, Wycombe and Stoke Mandeville Hospitals, Buckinghamshire Healthcare NHS Trust, Buckinghamshire, UK

\subsection{6/gutjnl-2014-307263.129}

Introduction Self expanding metallic stent (SEMS) placement effectively palliates malignant dysphagia, most commonly due to oesophageal cancer. Typically stents are placed under fluoroscopic guidance, but some centres use direct vision endoscopy as an alternative. ${ }^{1}$ There are however little data comparing the two techniques. At our 2-hospital institution, all patients presenting to Stoke Mandeville Hospital undergo radiologically guided stent placement, while patients at Wycombe Hospital undergo endoscopic placement without fluoroscopy. We describe our experience over a three year period.

Methods A retrospective observational study of all patients who underwent SEMS placement at our two hospitals over a three year period (2009-2012) was performed. 41 patients were included in the study, with placement of 48 SEMS. Improvement in dysphagia, survival and complication rates were the main outcome measures.

Results 21 patients underwent radiologically guided placement, 20 for oesophageal cancer, 14 male, median age 78 years. 20 patients underwent endoscopically guided placement, 17 for oesophageal cancer, 8 male, median age 80.5 years. Disease stage was similar in both groups, with metastases in 11/21 of the radiology group, and 10/20 of the endoscopy group. More patients in the radiology group had received prior radiotherapy (13 vs 8). Significant improvement in dysphagia was similar in both groups $(14 / 21$ radiology vs $14 / 20$ endoscopy, $p=0.82)$. There was no significant difference in median survival after stenting (135 vs 116 days, $\mathrm{p}=0.98$ ), or major 30 day complications defined as perforation, recurrent dysphagia or death $(5$ in both groups).

Conclusion Direct vision endoscopic SEMS placement was as effective as radiological guidance for dysphagia palliation at our institution, with a similar mortality and complication rate. This provides further evidence for the role of direct vision endoscopic SEMS placement in palliation of malignant dysphagia.

\section{REFERENCE}

1 Wilkes EA et al. Insertion of expandable metallic stents in esophageal cancer without fluoroscopy is safe and effective: a 5 year experience. Gastrointest Endosc. 2007 May;65:923-9

Disclosure of Interest None Declared.

\section{PTU-056 HIGHLY SUCCESSFUL, MINIMALLY INVASIVE ENTERAL ACCESS BY DOUBLE-BALLOON ENTEROSCOPY (DBE) AND LAPAROSCOPIC-ASSISTED DBE}

${ }^{1} \mathrm{TC}$ Shepherd*, ${ }^{1} \mathrm{O}$ Epstein, ${ }^{2} \mathrm{~A}$ Khan, ${ }^{2} \mathrm{ET}$ Pring, ${ }^{3} \mathrm{M}$ Varcada, ${ }^{3} \mathrm{~S}$ Rahman, ${ }^{2} \mathrm{EJ}$ Despott. ${ }^{1}$ Gastroenterology, Royal Free Hospital, London, UK; ${ }^{2}$ Endoscopy, Royal Free Hospital, London, UK; ${ }^{3}$ Academic Department of Surgery, Royal Free Hospital, London, UK

\subsection{6/gutjnl-2014-307263.130}

Introduction Patients with chronic gastroparesis frequently require prolonged enteral feeding via the jejunal route. This is often achieved through the placement of a percutaneous endoscopic gastrostomy with jejunal extension (PEG-J) or a surgically 